Meta

Journal des traducteurs

Translators' Journal

\title{
Trajectories of Research in Translation Studies
}

\section{Maria Tymoczko}

Volume 50, numéro 4, décembre 2005

Pour une traductologie proactive - Actes

For a Proactive Translatology — Proceedings

Por una traductología proactiva - Actas

URI : https://id.erudit.org/iderudit/012062ar

DOI : https://doi.org/10.7202/012062ar

Aller au sommaire du numéro

\section{Éditeur(s)}

Les Presses de l'Université de Montréal

ISSN

0026-0452 (imprimé)

1492-1421 (numérique)

Découvrir la revue

Citer cet article

Tymoczko, M. (2005). Trajectories of Research in Translation Studies. Meta, 50(4), 1082-1097. https://doi.org/10.7202/012062ar

\section{Résumé de l'article}

L'article pésente brièvement les principales directions, vraisemblablement productives, de la recherche en traductologie à venir au cours des prochaines décennies. Il comprend six grands volets. Le premier traite des tentatives de définir la traduction - c'est-à-dire les recherches concernant les particularités linguistiques de la traduction, les études de corpus, les études descriptives historiques ainsi que l'analyse des protocoles de traduction à haute voix. Le second se rapporte à l'internationalisation de la traduction, ce qui crée un défi pour les théories occidentales au sujet des présupposés de la traduction et produit de nouvelles études de cas ébranlant les fondements de la théorie et de la pratique telles que connues jusqu'à présent. Le troisième volet comprend des discussions sur les changements dans la théorie et la pratique de la traduction dûs à l'apparition de nouvelles technologies et à la mondialisation. Dans le quatrième volet, il s'agit d'application des théories interprétatives s'appuyant sur d'autres disciplines. Les deux derniers volets concernent la relation entre les études de traductologie avec les sciences cognitives et la neurophysiologie. En conclusion, quelques remarques d'ordre général au sujet de la recherche en traduction dans son ensemble et la structure des études en traductologie sont présentées.
Ce document est protégé par la loi sur le droit d'auteur. L'utilisation des services d’Érudit (y compris la reproduction) est assujettie à sa politique d'utilisation que vous pouvez consulter en ligne.

https://apropos.erudit.org/fr/usagers/politique-dutilisation/ 


\title{
Trajectories of Research in Translation Studies
}

\author{
MARIA TYMOCZKO \\ University of Massachusetts Amherst, Amherst, United States of America \\ tymoczko@complit.umass.edu
}

\begin{abstract}
RÉSUMÉ
L'article pésente brièvement les principales directions, vraisemblablement productives, de la recherche en traductologie à venir au cours des prochaines décennies. Il comprend six grands volets. Le premier traite des tentatives de définir la traduction - c'est-à-dire les recherches concernant les particularités linguistiques de la traduction, les études de corpus, les études descriptives historiques ainsi que l'analyse des protocoles de traduction à haute voix. Le second se rapporte à l'internationalisation de la traduction, ce qui crée un défi pour les théories occidentales au sujet des présupposés de la traduction et produit de nouvelles études de cas ébranlant les fondements de la théorie et de la pratique telles que connues jusqu'à présent. Le troisième volet comprend des discussions sur les changements dans la théorie et la pratique de la traduction dûs à l'apparition de nouvelles technologies et à la mondialisation. Dans le quatrième volet, il s'agit d'application des théories interprétatives s'appuyant sur d'autres disciplines. Les deux derniers volets concernent la relation entre les études de traductologie avec les sciences cognitives et la neurophysiologie. En conclusion, quelques remarques d'ordre général au sujet de la recherche en traduction dans son ensemble et la structure des études en traductologie sont présentées.
\end{abstract}

\begin{abstract}
The article sums up the principle trajectories of research in translation studies that are likely to be productive in the coming decades. I focus on six broad areas. The first encompasses attempts to define translation: this includes research as diverse as examinations of particular linguistic facets of translation, corpus studies of translation, descriptive historical studies, and analysis of think-aloud protocols. The second area of research pertains to the internationalization of translation, which challenges basic Western assumptions about the nature of translation and generates new case studies that shake the foundations of translation theory and practice as they are known at present. Changes in translation theory and practice associated with emerging technologies and globalization constitute the third research area to be discussed. The fourth strand is the application to translation of various interpretive perspectives based on frames from other disciplines. The last two branches of research have to do with the relationship of translation studies to cognitive science and neurophysiology. The article closes with some general observations about the implications for translation research as a whole and the structure of translation studies entailed by the six areas discussed.
\end{abstract}

\section{MOTS-CLÉS/KEYWORDS}

research developments, internationalization, emerging technologies, cognitive science

My subtitle to this essay might be "Meta in the next fifty years," for the purpose of the article is to offer an overview of the field of translation studies at present, as I see it, summing up the principle trajectories of research in translation studies that are likely to continue and to be productive in the coming decades. ${ }^{1}$ In a sense I am gazing into a crystal ball, a dangerous and heady endeavor, where the limitations of the gazer are 
always apt to be shockingly apparent. At the same time, it is necessary from time to time to try to see a field whole. Without such broad overviews scholars are at risk of ceasing to understand the structure of the discipline and the structure of its discoursive field, as well as the relationships of particular discourses within it. Such amnesia obviously affects both intellectual clarity and working relationships, impacting adversely on both students and colleagues, as well as on the practices that a field such as translation studies promulgates in the world.

In this article, therefore, I focus on six broad areas that serve to cluster areas of research that I believe will continue to be central to the structure of translation studies as a discipline in the next decades, as well as emergent areas of research that are even now apparent. ${ }^{2}$ The first area of research can broadly be called attempts to define translation: this includes research as diverse as examinations of particular linguistic facets of translation, corpus studies of translation, descriptive historical studies, and analysis of think-aloud protocols. The second area of research pertains to the internationalization of translation, which challenges basic Western assumptions about the nature of translation and generates new case studies that shake the foundations of translation theory and practice as they are known at present. Changes in translation theory and practice associated with emerging technologies and globalization constitute the third research area to be discussed. The fourth strand of research that will continue to be central in the field is the application to translation of various interpretive perspectives based on frames from other disciplines, as well as superordinate categories investigated by scholarship in other fields. The last two branches of research to be discussed have to do with the relationship of translation studies to cognitive science and neurophysiology; while there is a great deal of existing research relevant to translation in the former, the latter represents an exciting growth area that will be developed in the near future. The article closes with some general observations about the implications for translation research as a whole and the structure of translation studies that is entailed by the six areas discussed.

\section{Defining Translation}

One way to characterize research on translation during the last half century is to say that scholars in the field have been preoccupied in diverse ways with the task of defining translation. Such attempts at definition are not trivial: in any academic field definition is an essential element, for it is not possible to proceed with research either abstractly or concretely if scholars do not define or delimit the object of study. ${ }^{3}$ These questions have taken a variety of forms in the past, as indicated by a perusal of the contents of Meta and other publications in translation studies during the last 50 years.

If we look back at research on translation in the last half century, approaches that at times have been characterized as oppositional can be viewed not as antithetical but as contributing in complementary ways to the attempt to define translation, approaching a common problem from different directions. Thus, early research on translation centered on linguistic aspects of translation, exploring the nature of translation in relation to language and linguistics. As such it looked at linguistic asymmetries and anisomorphisms in translation interface, the language-specific nature of meaning as a factor in translation, the nature of communication in general and its 
relationship to the limitations of translation, and so on, all of which tended to delimit or establish the boundaries of the linguistic aspects of the task of the translator.

Similarly, literary or poetic approaches to translation constitute another cluster of attempts to define translation, focused on the parameters pertaining to literary questions and questions raised by complex and extended texts, as well as their intertexts and contexts. Thus, this school of research investigated issues such as how translation gets shaped or determined by the nature of literature; what practices translators use when translating different literary modes, forms, genres, and text types; how texts relate to literary traditions; and how texts relate to their contexts.

Still another research cluster attempting to define translation has concentrated on the investigation of cultural aspects of translation. It became clear early on that translation could not just be defined in terms of language or text type, but that it was essential to consider culture as well. Such approaches cannot be fully separated from either linguistic or literary approaches to translation, for language is central to constituting any human culture and literature in turn is rooted in both language and culture. ${ }^{4}$ Research orientations to culture have ranged from focusing on the translation of material culture to investigating sociolinguistic aspects of translating culture. ${ }^{5}$ Similarly, the attempt to demonstrate and define the way translation fits into and is affected by the largest frameworks of culture inspired the cluster of approaches to translation that are known as systems theory, the cultural turn, and, most recently, the power turn. ${ }^{6}$ Similarly, most "specialty" approaches to translation fit here as well, including investigations of translation and gender or translation in postcolonial contexts.

Often the definitional dimension of translation research projects has been obscured by the prescriptive packaging of the results, packaging that is usually intimately connected with the pedagogical orientations of the researchers. Nonetheless, if we look at such schools of research less as antithetical and more as engaging in a dialectic about the nature of translation, less as holding opposing positions about translation than as allied in a common enterprise of trying to define translation, it becomes easier to understand the history of translation research and also to position the various contemporary schools of research that have descended from these early endeavors. ${ }^{7}$ Whether focused primarily on translation processes or translation products, ${ }^{8}$ most theorizing and research about translation for the last half century has been motivated in part by the definitional impulse inherent in trying to characterize aspects of the activity of translation or of actual translations and then to generalize these aspects to translation as a whole.

What most translation scholars would like to believe is that the stage of defining translation is essentially over: it would be satisfying to think that the big parameters regarding translation have been sketched out. In part this is an attractive view because it would allow us to get on with our own particular specialized interests, say instructing students about how to do actual translations or researching a very comfortable corner of translation, such as translation in Ireland in my case. But in thinking about the trajectories of translation research in the future, I must be the bearer of bad news. This task of defining translation is not finished and it will continue to be a central trajectory of translation research in the decades to come.

Whether translation research takes the form of investigating the work of translators and the processes of translation or descriptive studies of actual translation products from various times, places, and cultural contexts, scholars continue to learn basic 
things about the phenomenon that we are researching, namely translation. Thus, there is a definitional component to most work on translation, whether it is basic research that generates data or the theorizing that attempts to interpret data and relate it to earlier research. Indeed it is the stark consideration of actual products and processes of translation over the centuries in many cultural environments that has tested, modified, and even overthrown many prescriptive or normative statements about translation in the contemporary world.

\section{An Excursus on Definition}

Because the definition of translation is intertwined with aspects of almost all research in the field of translation studies and thus with the rest of the points below, I want to digress to consider this question directly. I should make it clear that when I talk about defining translation, I am not merely thinking about agreeing on a dictionary definition for the word translation, though even that is a great deal more problematic than most people might think. I am also not talking about a quest to come up with a definition giving the necessary and sufficient conditions for translation as either process or product. In fact, as I have argued earlier in Meta, such a definition is impossible because translation, like the concept game, discussed by Wittgenstein, is an open concept (Tymoczko 1998:654-56). ${ }^{9}$

In cognitive science such open concepts are sometimes called cluster concepts or cluster categories. Cluster concepts, such as the concepts game and language, both discussed by Wittgenstein, have certain interesting characteristics. In discussing language Wittgenstein remarks, "I am saying that these phenomena have no one thing in common which makes us use the same word for all, - but that they are related to one another in many different ways. And it is because of this relationship, or these relationships, that we call them all 'language"' (1953:section 65, original emphasis). Wittgenstein indicates that a cluster concept such as game or language is comprised of "a complicated network of similarities overlapping and criss-crossing: sometimes overall similarities, sometimes similarities of detail... . I can think of no better expression to characterize these similarities than 'family ressemblances"' (section 66-67). Wittgenstein also uses the metaphor of a thread to characterize such concepts: "we extend our concept ... as in spinning a thread we twist fibre on fibre. And the strength of the thread does not reside in the fact that some one fibre runs through its whole length, but in the overlapping of many fibres" (section 67).

In order to project research trajectories in translation studies, it is necessary therefore to come to grips with the implications of the openness of the concept translation for the nature of research in the field and for the structure of the field as a whole. Because translation as a concept is open, for example, by implication translation studies itself is an open field and will remain so. There is a paradox here that suggests that research in the field is different from that envisioned in most fields: the definitional impulse in translation research must not aim at total closure, for if the concept of translation is open or fuzzy, then the findings of most research will have open aspects (or, conversely, narrow limits of applicability) and the field as a whole cannot ever achieve a fully circumscribed nature.

It follows that when I talk here about defining translation, I am talking about understanding the various features or aspects of translation processes that enter into 
many but not necessarily all translation products or all translation processes. The goal can only be an open definition, one that helps in understanding the nature of many translation processes and products, even if not all translation processes and products share a common core of specific features. The definitional impulse in translation research aims at indicating the extension of the concept translation, mapping some borders or boundaries or limits for the inquiry about translation, even if these borders do not form a closed figure.

A highpoint in the development of this definitional strand of research in translation studies was Gideon Toury's definition of translation as "any target language text which is presented or regarded as such within the target system itself, on whatever grounds" (Toury 1982:27; cf. Toury 1980:14, 37, 43-45). This definition is congruent with the notion of translation as a cluster concept, and it is important in part because it allows for cultural self-definition and self-representation in the field, elements that are central to the internationalization of the field of translation studies, discussed below. Toury's definition is also important because he offers an a posteriori approach to the problem of defining translation, which suits the pragmatic nature of cluster concepts like translation and, hence, points to the necessity of descriptive translation studies.

In the sense of defining translation I am discussing here, however, Toury's definition is not fully satisfying. We would like to know more about the nature of the concept of translation and to be able to say more about its (permeable) boundaries. We might like to know more, for example, about the range of translational phenomena, the sorts of things that enter into decisions by various cultures to identify certain phenomena as translations and reject others as not translations, the types of correlations there are between these identifications and other cultural processes and products, the correlations there are between such determinations and social conditions, and the like. Future research in translation studies inevitably will turn to such questions and others of the same type.

\section{The Internationalization of Translation Studies}

For at least 30 years, descriptive studies of translation have amassed large quantities of data showing that translation phenomena as they can be traced through history challenge and even partly contravene most theoretical and prescriptive models of translation developed for pedagogical practice in the field. The implication of this situation, of course, is that teachers do not teach what translation is in the present or has been in the past, but what it should be in the present, reflecting an investment in the idées reçues of the dominant (commerical, governmental, and so forth) powers of contemporary (Western, globalized) culture.

In the interim translation studies as a field has become steadily more internationalized. Ever more scholars from developing nations are active in the discipline professionally, publishing articles and contributing to conferences, as well as teaching translation in their home countries. The rise of English as a world language has contributed to this trend as well. Exciting trends in translation studies reflecting the increased internationalization are apparent in the conferences that have specifically focused on moving beyond Eurocentric perspectives, including the conference held in Montreal, "Postcolonial Translations: Changing the Terms of Cultural Transmission," 
sponsored by the Universite de Montréal and Concordia in 1997, and the invitational three-year seminar "Translations and Translation Theories East and West," sponsored jointly by the School of Oriental and African Studies (SOAS) and the University of London in 2001-03, among others. There are also more international conferences being held in developing countries, such as that in Baroda, India, in November 2005 on the topic "Asia in the Asian Consciousness: Translation and Cultural Transactions." The internationalization of the field is tangibly represented in publications that specifically look beyond the West, including the volumes edited by Sherry Simon and Paul St-Pierre, Changing the Terms (2000); Marilyn Gaddis Rose, Beyond the Western Tradition (2000); and Theo Hermans, Translating Others (forthcoming 2005). A sign of the increasing internationalization of translation studies is also the founding of the International Association of Translation and Intercultural Studies (IATIS), which held its first meeting in Korea in 2004, with the second scheduled for South Africa in 2006.

At the same time, there are troubling aspects to the internationalization of translation studies, for the movement has augmented a tendency for translation training throughout the world to be grounded in theory developed in Eurocentric environments and based on Eurocentric data, rather than the development of a broader spectrum of conceptualizations and practices. Often classic Western publications related to translation theory and practice - say books by Eugene Nida or Lawrence Venuti - are used in the classroom or shape the curriculum. The use of publications developed in the West can be seen as progressive or, alternately and more troubling, as a form of intellectual hegemony.

The reliance on and promulgation of Westernized perspectives in a field dedicated to intercultural communication and in a field becoming increasingly internationalized is clearly an unstable situation. I believe that the tension will inevitably result in major changes in translation research and scholarship over the next decades, and I see the trend taking several forms. First, the very nature of translation must be reconsidered as translation studies begins to explore the range of forms and practices that translation has assumed throughout the world over the centuries.

One can get some hint of this challenging aspect of the internationalization of translation studies by examining various non-Western words for 'translation' and considering the possible realignments that those words, together with their specific translation histories, suggest for theories of translation. In India, for example, two common words for translation are rupantar, 'change in form' and anuvad, 'speaking after, following'; Sujit Mukherjee (1994:80) indicates that neither of these terms implies fidelity to the original and that the concept of faithful rendering came to India with Christianity. By contrast, the current Arabic word for translation is tarjama, originally meaning 'biography', reflecting perhaps the early focus of Syriac Christian translators on the Bible, patristic texts, and lives of saints in the third to fifth centuries of the common era. The association of tarjama with a narrative genre, biography, to me indicates that the role of the translator is seen as related to that of a narrator, suggesting in turn the powerful potential of the translator's agency. Syriac translators eventually turned to other subjects as well, becoming major conduits of Greek science and philosophy to their contemporaries, and it is perhaps relevant that a second meaning of tarjama is 'definition'. This meaning may be related to the later involvment of Syriac translators with Greek learned texts, especially scientific and mathematical ones, for such texts are heavily oriented to defining and explaining objects of the 
natural and conceptual worlds. This meaning may also be relevant to early Syriac and Arabic translation practice, for the translators did not merely transmit Greek texts unchanged; when scientific and mathematical knowledge had progressed, translators augmented the Greek texts with their own culture's supplementary frameworks and advances, merging and recasting the Greek material so that the subject matter became better articulated and better defined in the translations. ${ }^{10}$

By contrast, in the Nigerian language Igbo, the words for translation are tapia and kowa. Tapia comes from the roots ta, 'tell, narrate', and pia, 'destruction, break [it] up', with the overall sense of 'deconstruct it and tell it (in a different form)'. Kowa has a similar meaning, deriving from $k o$, 'narrate, talk about' and wa, 'break in pieces'. In Igbo therefore translation is an activity that stresses the viability of the communication as narration, allowing for decomposition and a change in form rather than one-to-one reconstruction. ${ }^{11}$ This is merely a small sample of words in non-Western languages that are used for the concept translation, but they have radical theoretical implications for the conceptualization of the field of translation studies, as should be clear. $^{12}$

Moreover, as a result of the internationalization of translation studies, basic premises that have been generally accepted heretofore in translation studies must also be reexamined, ranging from the nature of the translation as an individualistic endeavor, to the focus on translation texts and translation as primarily a literacy practice, to the presupposition that the significant text types that translators must identify have been defined. ${ }^{13}$ Inevitably, complementing the realignments already discussed, more case studies will be developed pertaining to non-Western translation histories and translation practices that will broaden what has been learned thus far primarily from Eurocentric data. In turn, all of this material will be theorized (preferably by scholars from the cultures involved), thus changing translation studies from the ground up. Clearly these trends in translation research are related to the definitional trajectory that has been discussed, but internationalization of the field will take on its own life, developing a momentum and gravitas of its own.

\section{Responses to Technological Shifts and Globalization}

Although the openness of translation as a category may be a problem for some scholars who like precision and controlled or closed definitions, it is the openended nature of translation and its lack of precise boundaries that have allowed it to adapt to diverse cultural conditions, to diverse social functions, and to changing technologies as well. Such technological shifts include the momentous transition from orality to literacy and the transition from manuscript culture to print culture. The world has begun another immense transition of this type that is changing translation, the transition associated with current developments in information technologies and the media, ranging from new mass media to the Internet, from CAT systems to translation imperatives associated with globalization. A major branch of translation research and theorizing in the next decades will respond to the changes in the conceptualization and practice of translation associated with this transition, and research in translation and reevaluations of the nature of translation both as process and product in the coming decades will inevitably focus on these changes. Research has already begun on these topics, but can only accelerate. ${ }^{14}$ 
The new conditions have increasingly begun to shift the nature of the agent of translation away from the individualistic model that has dominated Western conceptualizations of the translator. When translation projects involve both multiple languages and high speed - as in the case of CNN that broadcasts in more than 40 languages and must turn stories around into all those languages in fewer than ten minutes or risk having local channels scoop them (on the basis of CNN's own breaking news broadcasts in English) - translation must become a decentered process conducted by teams of people linked electronically through technological systems, rather than by single individuals or even groups of individuals coordinating their efforts from a single place. Although the media epitomize emerging modes of translation, similar conditions obtain in many other situations, including scientific and technological domains; multinational corporations and advertising; multilingual political communities, such as the European Union; and communication domains having to do with global security and the military.

Theorization of these new shifts will profit from models introduced by the internationalization of translation studies. Where Western theory and practice has focused on the individual as the agent of translation, treating the translator as a sort of "black box" of linguistic transformation, translation processes in other cultural contexts present alternate possibilities. In oral societies, for example, the audience is always a "participatory" audience; thus "a text" does not belong to and is not produced solely by the one who makes the utterance. Similarly, in the Chinese cultural sphere, translation has been primarily a group process, rather than an individual one. Such international models of translation will serve as vital correctives for translation research pertaining to translation in a globalized world, realigning the field so as to allow it to move beyond the pretheoretical presuppositions of Western translation theory, including individualism. Indeed many non-Western translation histories offer models of translation processes that may be closer to those emerging at present, pointing the way to those that will become ascendent in the next decade.

Spurred by these technological shifts, translation research will reexamine the nature of the translator and the translation process, but there will be other productive research concerns pertaining to ascendant technologies and globalized conditions as well. For example, the very nature of language in translation must be reconsidered in view of the emergence of new forms of non-localized idioms, such as global English. Although global English has antecedents in world history - in, say, the official languages of earlier imperial civilizations such as those of Rome and China - the status and condition of such a lingua franca for the translator is changed radically by the immediacy and accessibility of the language through modern media which facilitate rapid dissemination - and hence rapid development and change - of such a language.

Finally, because of the new technologies, a major growth area will be research about the translation of materials that coordinate text and image. Such materials have increasingly become the norm in many areas of life: the media (including film, television, and the Internet), modes of disseminating information, advertising, business, and so forth. This is a research trend that has already begun and that will accelerate over the next decades: from a marginalized area of translation pertaining to areas such as film dubbing or subtitling and certain features of translating for the stage, this mode of translating will become increasingly paradigmatic, and research must follow suit. 
No doubt future media developments will present additional research questions that we cannot yet even foresee. One of the interesting theoretical implications of the growth of this branch of translation studies is that it will move translation interests increasingly away from interlingual translation toward intersemiotic translation, thus integrating Roman Jakobson's (1959) third category of translation more closely to mainline interests in translation studies and making it more central to translation research. The result will be yet another expansion of the concept translation, necessitating the retheorization of various aspects of the entire field of translation studies.

\section{Framing Translation and Superordinate Categories}

A fourth trajectory of translation research has to do with new methods of framing translation within the context of other areas of academic inquiry. The history of translation studies shows that research on translation has expanded periodically by adopting frames from other disciplines to facilitate new ways of looking at translation. The first impetus to modern research on the topic, for example, came from using frameworks from linguistics to look at translation. Other large frames have included systems theories, sociolinguistics, discourse theory, and cultural studies; examples of more specific or narrow-gauge frames are André Lefevere's (1982, 1985, 1992) development of the concept of refraction or rewriting to frame translation as a subject of research and the use of postcolonial theory as a means to explore certain translation situations. ${ }^{15}$

The use of frames in translation studies is not an accident. If we follow out the implications of seeing translation as a cluster concept, there are important implications for how research in the field can proceed. Scholars cannot expect to define the attributes or properties of translation in general or of all translations through the determination of necessary and sufficient conditions, as we have seen. It is, however, possible to explore the properties that characterize specific groups of translations or that various groups share with each other. Such an approach is facilitated by the adoption of frames of reference that subsume one or more groups of translation, thus illuminating many even though not all translations.

Framing translation in a variety of ways is therefore productive because it responds to the nature of translation as an open category and a cluster category. Although no one frame can suffice to illuminate all translations, a frame that is well chosen may illuminate a significant type of translations or a significant facet of the process of translation. Although no absolutes are possible in the case of a cluster concept, it is possible to illuminate characteristics shared by a significant segment of the category by approaching translation from the point of view of a superordinate or adjacent and partially overlapping category. Approaches of this type will continue in translation studies therefore of necessity.

In a sense each frame within which translation can be situated provides a lens for viewing translation, a lens that filters perception of particular phenomena and permits clarity of focus and description. In talking about games in particular and cluster categories in general, Wittgenstein enjoins his readers, "Don't say: 'There must be something common, or they would not be called "games"' - but look and see whether there is anything common to all. - For if you look at them you will not see something that is common to all, but similarities, relationships, and a whole series of them at 
that. To repeat: don't think, but look!” (1953: section 66, original emphasis). Here Wittgenstein points to the fact that membership in a cluster category is not a matter of logic but rather a function of practice and usage. Membership is an empirical question, not one based on theoretical criteria; this is why he says "don't think, but look!" But it is difficult to know how to see and what to look for in observing a large variety of objects. Perception is overdetermined. It is difficult to analyze raw empirical data unless one has an index to judge the data by. Frames and superordinate categories related to particular data focus perception and enable observation and analysis. They provide interpretive perspectives that allow researchers to look and see, a particularly important function in the case of research on a cluster category where definition of the object of study itself is problematic.

Let me give a specific example from my current work. As other scholars have done, one of the frames that I am currently exploring in relationship to translation is representation. I have been attempting to understand its relationship to specific translations, as well as its implications for theories of translation. ${ }^{16}$ The nature of representation as a frame makes manifest in part, for example, why translation is so powerful an act, why translation has played such powerful roles in many cultures throughout history, why translation is constitutive of reality, and why translation is associated with textual manipulation, as well as the interplay among these properties. This frame also illuminates aspects of the ethical dimension of translation and, in conjunction with insights from other frames, allows me to propose things about translation that would be impossible without seeing translation through the lens of this superordinate category.

As scholarship in other fields expands and develops new frames during the coming decades, additional frames relevant to translation will emerge, and they will provide new research opportunities for translation studies. This sort of development will be a continual impetus to research in the field. The key to successful research employing a particular frame or superordinate category is to understand that translation is only one instance of the larger category rather than viewing the category as an attribute of translation. This sounds obvious but not all examples of research using frames for translation have observed that distinction. Whether the superordinate category is language, discourse, or representation, it is the application to translation of insights from the larger frame of reference that usefully illumines aspects of translation.

This type of research promises to be an enduring part of translation studies. Investigation based on the framing of translation will become more systematic, more deliberate, more articulated, and more self-reflexive in future translation research as the field becomes more self-aware, more able to articulate its own nature, and more cognizant about the implications of the nature of translation as an open concept for the structuring of research about translation.

\section{Translation and Cognitive Science}

A fifth area of translation research that will continue and expand in the coming decades pertains to the relationship between translation and cognitive science. Although individual scholars have attempted to apply results from cognitive science to translation studies, the field as a whole is only at a beginning in recognizing the centrality of this relationship for understanding translation as a process. There are, 
of course, diverse branches of cognitive science, many of which have immediate relevance to translation practice and also implications for the understanding and assessment of translation products as well.

An example of the latter is the work in cognitive science on similarity and analogy, topics taken up at the conference "Similarity and Translation" in June 2001 in New York City, sponsored by the American Bible Society, the results of which have been published in Similarity and Difference in Translation, edited by Stefano Arduini and Robert Hodgson (2004). Understanding both similarity and difference in translation products and processes must obviously be informed by how human beings perceive similarity and difference in general. Research in cognitive science is extensive on these subjects and serves to illuminate the history of translation, translational criteria that have emerged over the last half century, and the very concept of equivalence used by translation scholars.

From the findings of research in cognitive science, it is apparent that equivalence in translation must be viewed as a similarity relationship (rather than an identity relationship), and research on similarity relationships by cognitive scientists illustrate the wide possibility of perceiving and constructing such relationships in translation. It is not possible to understand the nature of translation as an attempt to create a likeness to a source text without understanding the way that human beings process likenesses in general, including the way that perception of similarity is culture bound and related to categories of perception. Cognitive scientists have also shown that perception of similarity is dependent on long-term and immediate experience. The implications of this research are momentous for translation studies: it follows that similarity in translation can only reflect implicitly or explicitly a particular time, place, and set of cultural priorities.

Better interface with cognitive science on the question of similarity will therefore lead to a better understanding of what choices translators have and how such choices are made. In descriptive translation studies the interface will lead to greater acuity in the analysis of translation products. In translation pedagogy the result will be greater self-reflexivity, including a better understanding of the types of likenesses privileged within specific contexts and an awareness of the limitations of prescriptive approaches. The consequence will be greater flexibility in teaching students how to move between different perceptions of similarity and how to master multiple practices of creating similarity, prerequisite skills for translators in the rapidly changing world of the future.

This is but one example of the central issues in human cognition that have been extensively researched within cognitive science and that impinge on translation. The time has come for translation studies to move beyond endless ill-informed arguments about such topics and to interface more systematically and more deliberately with the cognitive sciences. I believe that this branch of translation research will be one of the most vigorous developing areas in translation research in the coming decades, in part because there are decades of established and tested research in cognitive science to assimilate and to relate to translation.

\section{The Neurophysiology of Translation}

Perhaps the most radically new and illuminating research in the coming decades will result from the investigation of translation by neurophysiologists. At present the activ- 
ity of individual translators continues to be opaque to scholars. Some clues are garnered by tracking the working choices of translators with computers that remember and time all work; other research attempts to open up the process by looking at translators' journals or recording their think-aloud protocols. But all these methods are primitive at best in indicating what actually occurs in the brain as translators move between languages.

Questions that arise include the following. How do the brains of bilinguals differ from those of monolinguals? Where and how are multiple languages stored in the brain? To what extent do translators store different languages in distinct parts of the brain and to what extent are diverse languages stored in an interpenetrating way? What happens when people move between languages in terms of brain patterns? What actual parts of the brain get activated during the process of translation? Does the pattern change as translators move through different stages of translation? How are translation processes similar to and different from ordinary linguistic processes? Do all translators operate using the same parts of the brain or do people vary widely in their cognitive modes and brain patterning? Is brain patterning during translation largely uniform across culture (and individuals within cultures) or does it differ radically from person to person, place to place? Do different types of translation involve similar or different sorts of brain activity? Is there a difference in linguistic transpositions with respect to orality versus literacy? Are there differences in neurological patterns characteristic of interpretation and textual translation?

This is but a small sampling of the kinds of questions that will shortly begin to be investigated by neurophysiologists and translation scholars working in concert. Even more radical possibilities will open up as the techniques of brain scans become more sophisticated and capable of greater delicacy. At present brain imaging - through MRI (magnetic resonance imaging) technology, PET (positron emission tomography) scans, and more traditional methods (such as experimentation with animals or working with patients suffering from brain lesions) - has begun to map the various parts of the brain and to correlate those parts with their functions. As yet the technology has not achieved the delicacy necessary to approach the questions that translation scholars would most like to have answered but the day is fast approaching when that will be possible. Neurophysiologists will soon be able to scan translators' brains as they actually work so as to begin to answer questions about translation processes, including those above. Moreover, once neurophysiology develops the capacities to describe the brain patterning associated with translation, it will be possible to conduct large scale experiments on the biology of translation.

These immensely powerful, interesting, and important areas of research opening up in the near future will radically change the way translation is thought about and approached. They will also radically change the structure of research in translation studies. Biologists interested in language, language acquisition, and bilingualism will become central players in translation studies. The locus of research will move from individuals to groups, and research teams will evolve that bring together translation scholars, cognitive scientists, literacy and language experts, and neurophysiologists. 


\section{Conclusions: Implications for Research Protocols and the Structure of Translation Studies}

Viewing translation studies from the perspective of research trajectories is interesting in part because it suggests new ways of understanding the structure of the field. Old traditional divisions and old rivalries fade in importance in light of new approaches to translation studies and emerging areas of research. The broad perspective afforded by an exercise such as the one undertaken here also makes it possible to see the field more whole: to see what has been accomplished in the past decades and what remains to be addressed in future.

It is now time to stand back even further and consider briefly commonalities suggested by the six areas projected as continuing and emerging branches of research in translation studies. What general principles can be articulated pertaining to the trajectories of translation research and the theorization that will follow? What is immediately obvious is that research in translation studies - as is the case in many fields - will become more and more interdisciplinary in its reach during the coming decades. Translation research will move away from linguistic approaches as narrowly conceived and even from the circumscribed cultural studies approaches currently in use. The growing edges of translation research will go beyond current approaches based on humanistic research, to embrace thoroughly diverse branches of the social sciences and natural sciences, particularly the biological sciences and technical aspects of cognitive science. What follows is that research in translation studies will increasingly require scholars with broader training than is currently customary in the field. It follows that not only is there the necessity to encourage students to become proficient in the social and natural sciences, as well as linguistic and textual subjects, but current teachers and scholars in translation studies must "retrofit" themselves by becoming more conversant with research in other fields so as to be able to transcend the current limitations of research in translation studies and remain at the cutting edge.

A second basic conclusion that follows from the research trajectories outlined, particularly the increasing internationalization of translation studies, is that Western researchers must move beyond Western parochialisms and become more receptive to facets of translation that are revealed in international practices and histories of translation. This involves interrogating the pretheoretical assumptions about translation based on Western theory and practice and becoming much more self-reflexive in understanding the subject positions and the places of enunciation that characterize Western discourses about translation. Western scholars must also be willing to share leadership of the field with scholars from outside the Eurocentric world. By contrast, scholars from non-Eurocentric domains must become more aware of the possibility, even the temptation, of hegemony in their approaches to the field: of accepting in uncritical ways the received positions on translation theory and practice that are linked to Western domination and that do not accord with local traditions of translation. It is particularly important not to foster hegemony through teaching practices that spread Western norms and practices of translation internationally, especially when such materials may have limited application in the world as a whole and when they may be particularly suited to the practices of multinational economic and military interests. There are not only ethical imperatives for caution here but intellectual 
ones as well. Implicit and untested presuppositions inherited from specific Western cultural contexts limit the understanding of translation as a complex and varied phenomenon and, hence, the ability to do sound research.

A third set of implications for research in translation studies relates to the notions of translation as a cluster concept and translation studies as an open field. Reflection on these matters suggests that research programs and the structure of research projects in translation studies will become increasingly diverse as the field develops. In the limiting case, in fact, the very openness of translation studies implies that every project must have its own research requirements and research design.

To facilitate the greater diversity of translation studies in all these respects, the field must become more sophisticated about the structures and protocols of research itself. Researchers within the field must better master scientific methodologies in general. There is a particular need to specify the domains of applicability of conclusions in an open field where the object of study is a cluster concept. Not all conclusions of research are applicable to all translation types or all translation contexts. It follows as well that the field should give up the search for universals. Greater attention must also be paid to margins of error, and the field must achieve greater consensus on principles of validation used in research. ${ }^{17}$ Such topics should become overt aspects of the scholarly discourses in the field. That is, there must be more metaconversations about research in the field of translation studies. ${ }^{18}$

It is obvious from what has been said that it is not appropriate to have static and formulaic approaches to project after project of translation research, as have at times been proposed and even practiced in the field. ${ }^{19}$ Similarly, research based on a supposed list of "comprehensive features" cannot become canonical because translation itself changes so much from one type of translation to another type within the cluster concept of translation. Instead the field must move increasingly to symptomatic readings and sophisticated sampling techniques, and researchers must understand the structures of research well enough to know how to design and implement such features in their research projects.

Finally, the implications of these research trajectories for pedagogy in translation studies are enormous. Many of the discourses of translation teaching will be altered in future. If translation is a cluster concept, there can be no invariant core in translation processes or products, and equivalence must be seen as a similarity relationship contingent on many aspects of the cultural context, a relationship that must be deliberately constituted by the translator. The necessity of teaching students how to make translation choices will become central to teaching methods as teachers move away from prescriptive approaches, teaching students the broadest possible outlook on translation types and practices, as well as flexibility in translation techniques, as befits practitioners of a field with a cluster concept at its core. It is clear that teachers can only harm their students if they persist in limiting students' understanding of translation through a rigid pedagogy. Instead, teachers should be clear about the limitations of their premises about and frameworks for translation, if only so that students will be prepared for a future that will inevitably entail changes in translation canons, translation strategies, and translation technologies as the definition of translation is increasingly elaborated. 


\section{NOTES}

1. This article began as a keynote address at the conference "Meta 50: Pour une traductologie proactive," held in Montreal April 7-9, 2005. I would particularly like to thank André Clas for making the essay possible.

2. Many of the topics discussed below are treated at greater length in my forthcoming study, Englarging Translation, Empowering Translators.

3. The question of how to define translation has been a major area of contention in translation studies; many scholars, for example, want to limit research to very restricted definitions of translation, such as translation as practiced by professional translators or translation as it is used commercially (a hegemonic version of translation). Others argue for a broader definition, including literary translation, past historical practices, community interpretation, and the like.

4. In fact cultural facets of translation get raised early on by linguists. Consider, for example, the discussion of cheese in Jakobson (1959).

5. In this sense, therefore, functionalist theories of translation, including those espoused by Eugene Nida, would have to be considered in part within a cultural orientation to translation. Cf. Nida (1964); Nord (1997).

6. See, for example, Hermans (1999), Bassnett and Lefevere (1990), Tymoczko and Gentzler (2002).

7. The result is, of course, what has been called "an interdiscipline." See Snell-Hornby (1988); SnellHornby, Pöchhacher, and Kaindl (1994).

8. This is a basic research distinction in translation studies discussed in Holmes (1994: 66-80).

9. See also my forthcoming book, ch. 1 .

10. On the practices of the Syriac and Arabic translators, see Montgomery (2000). I am also indebted here to Abdulzahra Muhamad, personal communication.

11. I am indebted for this information to Isidore Okpewho, personal communication.

12. For more examples and their implications, see Tymoczko forthcoming.

13. See Tymoczko (2005) for a discussion of many pretheoretical assumptions about translation that are not compatible with a genuinely international perspective on translation.

14. See, for example, Cronin (2003); these topics have also become staples of current international conferences on translation.

15. On postcolonial translation studies, see Tymoczko $(1999,2000)$, and sources cited.

16. A more detailed discussion is found in Tymoczko (2005), as well as Tymoczko forthcoming, ch. 2.

17. A more extensive discussion of these issues is found in Tymoczko forthcoming.

18. A good example of the sort of dialogue that should be increased can be found in Olohan (2000) and Hermans (2002), the two volumes of papers that emerged from "Research Models in Translation Studies," a productive conference sponsored by UMIST and University College London in Manchester, England, in 2000.

19. See the analysis of the early years of descriptive translation studies in Hermans (1999).

\section{REFERENCES}

Arduini, S. and R. Hodgson JR. (eds.) (2004): Similarity and Difference in Translation, Rimini, Guaraldi.

Bassnett, S. and A. Lefevere (eds.) (1990): Translation, History and Culture, London, Pinter.

Cronin, M. (2003): Translation and Globalization, London, Routledge.

Hermans, Th. (1999): Translation in Systems: Descriptive and System-oriented Approaches Explained, Manchester, St. Jerome.

— (ed.) (2002): Crosscultural Transgressions: Research Models in Translation Studies II: Historical and Ideological Issues, Manchester, St. Jerome Publishing.

— (ed.) (2005): Translating Others, Manchester, St. Jerome.

Holmes, J. S. (1994): Translated! Papers on Literary Translation and Translation Studies, Amsterdam, Rodopi.

Jakobson, R. (1959): “On Linguistic Aspects of Translation,” On Translation, Ed. R. A. Brower, Cambridge, Harvard University Press, p. 232-239.

Lefevere, A. (1982): "Literary Theory and Translated Literature," The Art and Science of Translation, Ed. A. Lefevere and K. D. Jackson, Dispositio 7, special issue, p. 3-22. 
- (1985): "Why Waste Our Time on Rewrites? The Trouble with Interpretation and the Role of Rewriting in an Alternative Paradigm," The Manipulation of Literature: Studies in Literary Translation, Ed. Th. Hermans, London, Croom Helm, p. 215-243.

- (1992): Translation, Rewriting, and the Manipulation of Literary Fame, London, Routledge.

Montgomery, S. L. (2000): Science in Translation: Movements of Knowledge through Cultures and Time, Chicago, University of Chicago Press.

Mukherjee, S. (1994): Translation as Discovery and Other Essays on Indian Literature in English Translation, London, Sangam Books.

NidA, E. A. (1964): Toward a Science of Translating: With Special Reference to Principles and Procedures Involved in Bible Translating, Leiden, E. J. Brill.

Nord, C. (1997): Translating as a Purposeful Activity: Functionalist Approaches Explained, Manchester, St. Jerome.

Olohan, M. (ed.) (2000): Intercultural Faultlines: Research Models in Translation Studies I: Textual and Cognitive Aspects, Manchester, St. Jerome Publishing.

Rose, M. G. (ed.) (2000): Beyond the Western Tradition, Binghamton, SUNY Binghamton, Center for Research in Translation.

Simon, S. and P. St-Pierre (eds.) (2000): Changing the Terms: Translating in the Postcolonial Era, Ottawa, University of Ottawa Press.

Snell-Hornby, M. (1988): Translation Studies: An Integrated Approach, Amsterdam, John Benjamins.

Snell-Hornby, M., F. Pöchhacker and K. Kaindl (eds.) (1994): Translation Studies: An Interdiscipline, Amsterdam, John Benjamins.

Toury, G. (1980): In Search of a Theory of Translation, Tel Aviv, Porter Institute for Poetics and Semiotics.

- (1982): "A Rationale for Descriptive Translation Studies." The Art and Science of Translation, Ed. A. Lefevere and K. D. JACKson, Dispositio special issue 7, p. 22-39.

түмосzко, M. (1998): "Computerized Corpora and the Future of Translation Studies," The Corpus-Based Approach, Ed. S. Laviosa, Special issue of Meta 43-4, p. 652-659.

- (1999): Translation in a Postcolonial Context: Early Irish Literature in English Translation, Manchester, St. Jerome.

- (2000): "Translation and Political Engagement: Activism, Social Change and the Role of Translation in Geopolitical Shifts," The Translator 6-1, p. 23-47.

- (2005): "Enlarging Translation Theory: Integrating Non-Western Thought about Translation," Translating Others. Ed. Th. Hermans, Manchester, St. Jerome.

- (Forthcoming): Enlarging Translation, Empowering Translators, Manchester, St. Jerome.

Tyмосzко, M. and E. Gentzler (eds.) (2002): Translation and Power, Amherst, University of Massachusetts Press.

Wittgenstein, L. (1953): Philosophische untersuchungen, Philosophical Investigations, Trans. G.E.M. Anscombe, New York, Macmillan. 